\title{
Intrapartum care of the HIV-positive woman
}

\author{
Kelsey E. Mills MD, Mark H. Yudin MD MSc
}

\section{The number of HIV-positive women in Canada is rising}

In 2011, 71300 Canadians were HIV positive, and 16600 were women. This number increased from 14740 women in 2008. In 2009, 177 infants were born to HIV-positive mothers. ${ }^{1}$ It is important that all HIV-positive women receive access to women-specific HIV/AIDS services. $^{2}$

HIV-positive women with an undetectable viral load can be encouraged to pursue a vaginal delivery

It is important to discuss mode of delivery and to assess viral loads in late pregnancy. ${ }^{3,4}$ The likelihood of perinatal transmission in women with an undetectable viral load is $0.1 \%-1.2 \%,{ }^{2}$ and women can be supported to pursue a vaginal delivery, with cesarean delivery for obstetric indications only. See Box 1 for indications for elective cesarean delivery.

Box 1: Indications for elective cesarean delivery in HIV-positive women at 38 weeks' gestation ${ }^{3}$

- No antepartum antiretroviral therapy

- Prior antiretroviral monotherapy

- Detectable viral load above 1000 copies/mL

- No prenatal care

- Patient request for cesarean delivery

A physician resources list is available in Appendix 1 (www.cmaj.ca/lookup/suppl/doi:10.1503 /cmaj.131062/-/DC1).

\section{Intrapartum pharmacotherapy is part of the strategy to reduce perinatal transmission}

HIV-positive women should be given highly active antiretroviral therapy (HAART) during pregnancy and during labour. ${ }^{3,4}$ In recent American guidelines, intravenous zidovudine treatment is no longer recommended during labour for women with a viral load below 400 copies $/ \mathrm{mL} .{ }^{3}$ In Canada, such treatment continues to be recommended for all women in labour and before cesarean delivery. ${ }^{4}$

\section{Invasive intrapartum procedures should be minimized}

To minimize the theoretical risk of perinatal transmission from exposure to maternal blood, invasive procedures (e.g., the use of fetal scalp electrodes, fetal scalp blood gas sampling, intrauterine pressure catheters and instrumental delivery) should be avoided when possible. ${ }^{2}$

\section{References}

1. Summary: estimates of HIV prevalence and incidence in Canada, 2011. Ottawa (ON): Public Health Agency of Canada; 2011.

2. Carter AJ, Bourgeois S, O'Brien N, et al.; CHIWOS Research Team. Women-specific HIV/AIDS services: identifying and defining the components of holistic service delivery for women living with HIV/AIDS. J Int AIDS Soc 2013;16:17433.

3. Panel on Treatment of HIV-Infected Pregnant Women and Prevention of Perinatal Transmission. Recommendations for use of antiretroviral drugs in pregnant HIV-1-infected women for maternal health and interventions to reduce perinatal HIV transmission in the United States. Washington (DC): US Department of Health and Human Services. Available: http://aidsinfo.nih.gov/contentfiles/lvguidelines /PerinatalGL.pdf (accessed 2013 June 30).

4. Burdge DR, Money DM, Forbes JC, et al.; Canadian HIV Trials Network Working Group on Vertical HIV Transmission. Canadian consensus guidelines for the care of HIV-positive pregnant women: putting recommendations into practice. CMAJ 2003;168:1683-8.

5. International Perinatal HIV Group. Duration of ruptured membranes and vertical transmission of HIV-1: a meta-analysis from 15 prospective cohort studies. AIDS 2001;15:357-68.

6. Mark S, Murphy KE, Read S, et al. HIV mother-tochild transmission, mode of delivery, and duration of rupture of membranes: experience in the current era. Infect Dis Obstet Gynecol 2012;2012:267969. doi:10.1155/2012/267969.

\section{A longer duration of ruptured membranes can be safe in HIV- positive women with undetect- able viral loads}

In 2001, a meta-analysis of data from 15 prospective cohort studies showed a $2 \%$ increased risk of perinatal transmission for every hour of ruptured membranes. Based on this, a shorter duration of ruptured membranes was recommended for HIV-positive women. However, many of the women in those studies had unknown viral loads, and many did not receive HAART. Thus, the results have limited applicability to the current era, in which most pregnant HIV-positive women are taking HAART and have undetectable viral loads. ${ }^{5}$ A recent Canadian study found no instances of perinatal transmission among women with a viral load below 1000 copies/mL, irrespective of the duration of ruptured membranes. ${ }^{6}$

\section{Competing interests: None declared.}

This article has been peer reviewed.

Affiliation: Department of Obstetrics and Gynaecology, University of Toronto (Mills, Yudin) and St. Michael's Hospital (Yudin), Toronto, Ont.

Correspondence to: Mark Yudin, yudinm @ smh.ca

CMAJ 2014. DOI:10.1503/cmaj.131062 